\section{BMJ Global Health}

\title{
Measuring primary healthcare expenditure in low-income and lower middle-income countries
}

\author{
Nathalie Vande Maele, ${ }^{1} \mathrm{Ke} \mathrm{Xu},{ }^{1}$ Agnes Soucat, ${ }^{1}$ Lisa Fleisher, ${ }^{2}$ Maria Aranguren, ${ }^{\oplus 1}$ \\ Hong Wang ${ }^{3}$
}

\begin{abstract}
To cite: Vande Maele $\mathrm{N}$,
Xu K, Soucat A, et al. Measuring primary healthcare expenditure in low-income and lower middle-income countries. BMJ Glob Health 2019;4:e001497. doi:10.1136/ bmjgh-2019-001497
\end{abstract}

Handling editor Seye Abimbola

Received 12 February 2019 Revised 20 February 2019 Accepted 20 February 2019

\section{Check for updates}

(C) Author(s) (or their employer(s)) 2019. Re-use permitted under CC BY-NC. No commercial re-use. See rights and permissions. Published by BMJ.

${ }^{1}$ Health Systems Governance and Financing, Organisation mondiale de la Sante, Geneve, Switzerland

${ }^{2}$ Freelance consultant, Washington, District of Columbia, USA

${ }^{3}$ Global Development Division, The Bill and Melinda Gates Foundation, Seattle, Washington, USA

Correspondence to Nathalie Vande Maele; vandemaelen@who.int

\section{ABSTRACT}

Primary healthcare (PHC) is considered as the pathway to Universal Health Coverage (UHC) and to achieving sustainable development goals. Measuring PHC expenditure is a critical first step to understanding why some countries improve access to health services, provide financial risk protection and achieve UHC. In this paper, we tested and examined different measurement options using the System of Health Accounts (SHA) 2011 for systematic monitoring of PHC expenditure. We used the 'first-contact' approach to PHC and applied it to the healthcare function or healthcare provider classifications of SHA 2011. Data comes from 36 recent low-income and middle-income countries health accounts 2011-2016. Country spending on PHC varies largely, across countries and across definition options. For example, PHC expenditure ranges from US $\$ 15$ to US $\$ 60$ per capita. The sensitivity analysis highlighted the weight of including or excluding medical goods. The correlation analysis comparing countries ranking is strong between options. The study identified the major challenges in developing standard monitoring of PHC expenditure. One, there is a lack of clear operational definition for PHC, suggesting that a global standard definition would not replace the need for country context specific definition. Two, there is insufficient data granularity both because the standard framework does not offer it and because quality data breakdown is unavailable.

\section{INTRODUCTION}

The 1978 Alma Ata Declaration on Primary Healthcare (PHC) was touted as an integral step to achieving health for all (WHO, 1978). More recently, the 2008 World Health Report, followed by World Health Assembly resolutions, and the Sustainable Development Goals (SDGs) re-emphasised the importance of PHC in recognition that regardless of a country's income, most health conditions can be addressed via primary care interventions. ${ }^{12}$ Literature review indicates that PHC is now more and more recognised as the foundation of any health system and as the most effective, efficient and equitable approach to

\section{Key questions}

\section{What is already known?}

- Measuring expenditure on PHC in a comparative and standard manner is a critical first step to understanding why some countries health system performance and health outcomes are doing better than others and where extra efforts can be made to gain better performance.

- To date, monitoring of primary health care (PHC) expenditure is nonexistent. Some countries such as India have attempted to track spending on primary health care, but there is no standardmethodology that allows comparisons between countries and across time.

\section{What are the new findings?}

- The global debate on the definition of PHC is evolving, and this paper proposes to work on identifying an operational definition for measuring PHC expenditure, which will help provide a global standard for comparison between countries and across time and there by contribute to progress in achieving the SDGs.

- Based on the HC and HP classification, we explore eight definitional options for PHC in this paper, with six options based on health services (HC classification), and two options based on health care providers (HP classification). Of all components (services or providers) included in the definition, outpatient care and medical goods are the largest.

- On average PHC expenditure in 36 low- and middle-income countries ranged from15 to 60 USD per capita, and from $31 \%$ to $88 \%$ of Current Health Expenditure CHE.

\section{What do the new findings imply?}

- The lack of a clear operational definition of PHC poses a challenge for standard monitoring of investments made towards PHC. Further research and analysis would provide a clearer operational definition of PHC expenditures and more distinct primary health care boundaries.

delivering essential health services to most of the population for the lowest cost. ${ }^{1-10}$

Furthermore, $\mathrm{PHC}$ is now considered as a pathway to Universal Health Coverage (UHC) 
and to achieving the SDGs. Increasing spending on PHC services (especially from domestic sources to improve the sustainability of financing) is advocated by many policymakers. ${ }^{4911}$ Yet, there is considerable global debate about how to define PHC and how PHC service delivery should be structured and organised. ${ }^{2912}$

Measuring expenditure on PHC in a comparative and standard manner is a critical first step to contributing to understanding why some countries health system performance and health outcomes are doing better than others and where extra efforts can be made to gain better performance. However, there is no framework for countries to use to guide systematic data collection or routine tracking of the funds spent specifically on PHC. ${ }^{13} 14$ The System of Health Accounts (SHA) $2011^{15}$ is commonly used as the global standard in tracking health expenditure, but PHC is not a category under any of the classifications. Rather, the components of PHC are included under different SHA 2011 classifications.

This paper provides insights on tracking PHC expenditure through a careful comparison of different methods using SHA 2011 framework. It is structured in four sections. After the introduction section, the second section describes methods and data sources, the third section presents results and the last section provides the discussion.

\section{METHODS}

\section{Patient and public involvement statement}

We did not involve patients or the public in our work.

\section{Operational definition of PHC}

The global community is looking to compare countries spending on PHC. The absence of a clear operational definition for implementing PHC as defined in Astana in October 2018 challenges the implementation of a standard monitoring approach. This paper therefore proposes to test various options for measuring PHC expenditure, using the SHA 2011 to help develop a global standard for comparison between countries and across time and thereby contribute to progress in achieving the SDGs.

The set of values identified as the foundation of PHC in the Alma Ata Declaration of 1978 and reiterated in Astana on 25-26 October 2018, including social justice and the right to better health for all, participation and solidarity, remain fully valid today. Over the past four decades, the spirit of PHC translated into health system strengthening approaches endorses principles of people centeredness, continuity, coordination and comprehensiveness of care. The impact and need to address the social determinants on health (beyond the health sector) were also recognised. ${ }^{16}$

An operational definition for measuring PHC expenditure should have the following properties: the scope is clearly defined; expenditure is measurable; data is comparable across countries and over time and results should trigger policy discussions and facilitate problem diagnosis. To date, there exists no easily measurable operational definition of PHC. For example, the recent Astana declaration ${ }^{17}$ states that PHC is about health services that are high quality, safe, comprehensive, integrated, accessible, available and affordable for everyone and everywhere and are provided with compassion, respect and dignity by health professionals who are well trained, skilled, motivated and committed. This does not translate to types of health services (eg, outpatient care) or types of providers (eg, ambulatory healthcare providers). Yet, monitoring expenditure by service or by provider is the most feasible way to construct an operational definition of PHC that is measurable and comparable. As a proxy, we propose to monitor expenditure on 'first-contact' services. It should be noted that the 'first contact' is not restricted to the first level of healthcare provider that a patient might encounter when seeking care. Health system service delivery function is about what services are delivered and through which mode of provision. Depending on the specific setting and service delivery arrangement in a country, the first contact could happen at any level of service providers.

\section{Accounting method}

SHA 2011 provides the international accounting standards in recording health expenditure. The boundaries of health expenditure in SHA 2011 framework are defined by the primary purposes of the consumption of the healthcare goods and services (all activities with the primary purpose of improving, maintaining and preventing the deterioration of the health status of persons and mitigating the consequences of ill-health through the application of qualified health knowledge). Some elements that could be considered PHC are not included, such as water and sanitation and neither are most of the social determinants on health. While there is no ready-made SHA 2011 classification for PHC, components of PHC expenditure can be identified within the SHA 2011 framework. The healthcare function (HC) and healthcare provider (HP) classifications can be used to define PHC expenditure for cross-country comparisons. It should be noted that in the SHA 2011 framework, capital and current expenditures are separated. Both HC and HP classifications exclude capital investment expenditure as the focus is on the consumption of the health services in a given period, set at 1 year.

The functional classification refers to the purpose of activities and helps delineate the activities that are to be considered as health expenditures. Health expenditure is defined as all activities with the primary purpose of improving, maintaining and preventing the deterioration of the health status of persons and mitigating the consequences of ill health through the application of qualified health knowledge. The basic dividing lines for structuring healthcare functions are individual versus collective healthcare goods and services, the basic purposes of care (eg, curative, rehabilitative, long-term care) and the 
modes of provision (eg, inpatient, outpatient). Governance and administration of the health system and its financing are also one of the categories under the $\mathrm{HC}$ classification.

The following groups of healthcare activities are under HC classification:

- Health promotion and prevention.

- Diagnosis, treatment, cure and rehabilitation of illness.

- Caring for persons affected by chronic illness.

- Caring for persons with health-related impairment and disability.

- Palliative care.

- Providing community health programmes.

- Governance and administration of the health system. Based on the concept of first contact, PHC expenditure could also be measured using the classification of HP. The HP classification encompasses organisations and actors that deliver healthcare goods and services as their primary activity, as well as those for which healthcare provision is only one among several activities. The principal activity exercised is the basic criterion for classifying HPs. The classification of HPs includes all organisations that contribute to the provision of healthcare goods and services and the purpose of the HP classification is to categorise country-specific provider units into a common, internationally comparable set of categories. However, huge challenges exist. For example, hospitals, which are major healthcare providers, usually offer not only inpatient healthcare services but also outpatient care, rehabilitation, long-term care services and so on.

SHA 2011 proposes the following HP classification:

- Hospitals.

- Residential long-term care facilities.

- Ambulatory care providers.

- Ancillary services providers, retailers and other providers of medical goods.

- Preventive care providers.

- Secondary providers (providers of health system administration and financing; households; non-health related industries).

Within the SHA 2011 framework, expenditure on services (HC) or providers (HP) can be cross-tabulated with a classification of revenue sources for health expenditure (FS). The FS classification includes three broad categories: domestic government, domestic private expenditure and external funding. The cross-classification (ie, between FS and HP or FS and HC) provides essential information on who finances PHC. Given the importance and commitment to $\mathrm{PHC}$, the government spending on PHC from domestic sources is one of the most looked for indicators.

\section{Options for defining PHC expenditure using SHA 2011 classification}

We led a series of technical discussions and consultations to support the development of an operational definition to monitor PHC expenditure using SHA 2011. The process lasted for about 1 year and included feedback from healthcare practitioners, policymakers and technical experts from countries across the world affiliated with specific health programme, international organisations and research institutes. While recognising the huge difference in health system structures and development across countries, some common understandings emerged. Based on the $\mathrm{HC}$ and HP classification, we explore eight definitional options for PHC in this paper, with six options based on health services (HC classification) and two options based on HPs (HP classification).

Option 1 includes general outpatient curative care, general dental curative care, home-based curative care, long-term outpatient and home-based care and preventive care (table 1). Option 1 serves as the basis for all further options. Options 2-6 are built on option 1 and only add other health services. Option 2 is marginally different from option 1 with ancillary and rehabilitation services added. Option 3 adds medical goods provided outside of healthcare services (typically purchased in pharmacies) to option 1 and option 4 adds a share of the health system governance services to option 1, using the percentage of $\mathrm{PHC}$ over the current health expenditure (CHE) (HC. $7 \times \mathrm{PHC} / \mathrm{CHE}$ ). Option 5 represents the combination of option 3 and 4 jointly. However, both medical goods purchased outside of a health service and governance services are not exclusively for PHC. As a result, we further tested the sensitivity of adding these expenditures in PHC by comparing adding $100 \%$ or less of each expenditure category. Option 6 is constructed in the reverse: it includes all services but inpatient services.

Options 7 and 8 are constructed from the classification on expenditure by provider. Option 7 monitors PHC from expenditure on providers of ambulatory healthcare, retailers and providers of preventive care. Option 8 is constructed in the reverse: it includes all providers except hospitals.

\section{Data source and variables of interest}

The study was based on available data from SHA 2011 country health accounts in 36 low-income and middle-income countries where breakdown items are available for constructing $\mathrm{PHC}$ expenditure. Countries include in this study are Armenia, Burundi, Benin, Burkina Faso, Bhutan, Côte d'Ivoire, Cameroon, DRC, Congo, Cabo Verde Republic of, Ethiopia, Micronesia (Federated States of), Ghana, Guinea, Gambia, Guinea-Bissau, India, Cambodia, Lao People's Democratic Republic, Liberia, Sri Lanka, Mali, Mauritania, Malawi, Niger, Nigeria, Nepal, the Philippines, Sudan, Senegal, Sierra Leone, Togo, Tunisia, United Republic of Tanzania, Uganda and Zambia.

Estimates for each option were constructed from country health accounts, covering expenditure between 2011 and 2016. Where data are available for multiple years, we use the most recent year. Country data includes a breakdown of health expenditure by healthcare service (HC) and expenditure by provider (HP). 
Table 1 Presentation of the options tested for monitoring $\mathrm{PHC}$ expenditure

\begin{tabular}{|c|c|c|c|c|c|c|c|c|}
\hline \multirow[b]{2}{*}{$\begin{array}{l}\text { Option name } \\
\text { and number }\end{array}$} & \multicolumn{6}{|c|}{ HC-based options } & \multicolumn{2}{|c|}{ HP-based options } \\
\hline & $\begin{array}{l}\text { PHC } \\
\text { basic } \\
\text { Option 1 }\end{array}$ & $\begin{array}{l}\text { 1+rehab } \\
\text { and } \\
\text { ancillary } \\
\text { Option } 2\end{array}$ & $\begin{array}{l}\text { 1+medical } \\
\text { goods } \\
\text { Option } 3\end{array}$ & $\begin{array}{l}\text { 1+admin } \\
\text { Option } 4\end{array}$ & $\begin{array}{l}\text { 1+med. } \\
\text { and } \\
\text { admin } \\
\text { Option } 5\end{array}$ & $\begin{array}{l}\text { All but } \\
\text { inpatient } \\
\text { care } \\
\text { Option } 6\end{array}$ & $\begin{array}{l}\text { PHC } \\
\text { providers } \\
\text { Option } 7\end{array}$ & $\begin{array}{l}\text { All but } \\
\text { hospitals } \\
\text { Option } 8\end{array}$ \\
\hline
\end{tabular}

SHA 2011 items

General outpatient, dental, home-based curative care; long-term outpatient and home-based care and preventive care

Medical goods not specified by function

Rehabilitative outpatient and home-based care; ancillary services not specified by function

Health system and financing administration

All services, including those mentioned above, except inpatient

Ambulatory and preventive care providers and medical goods retailers

All providers, including those mentioned above, except hospitals

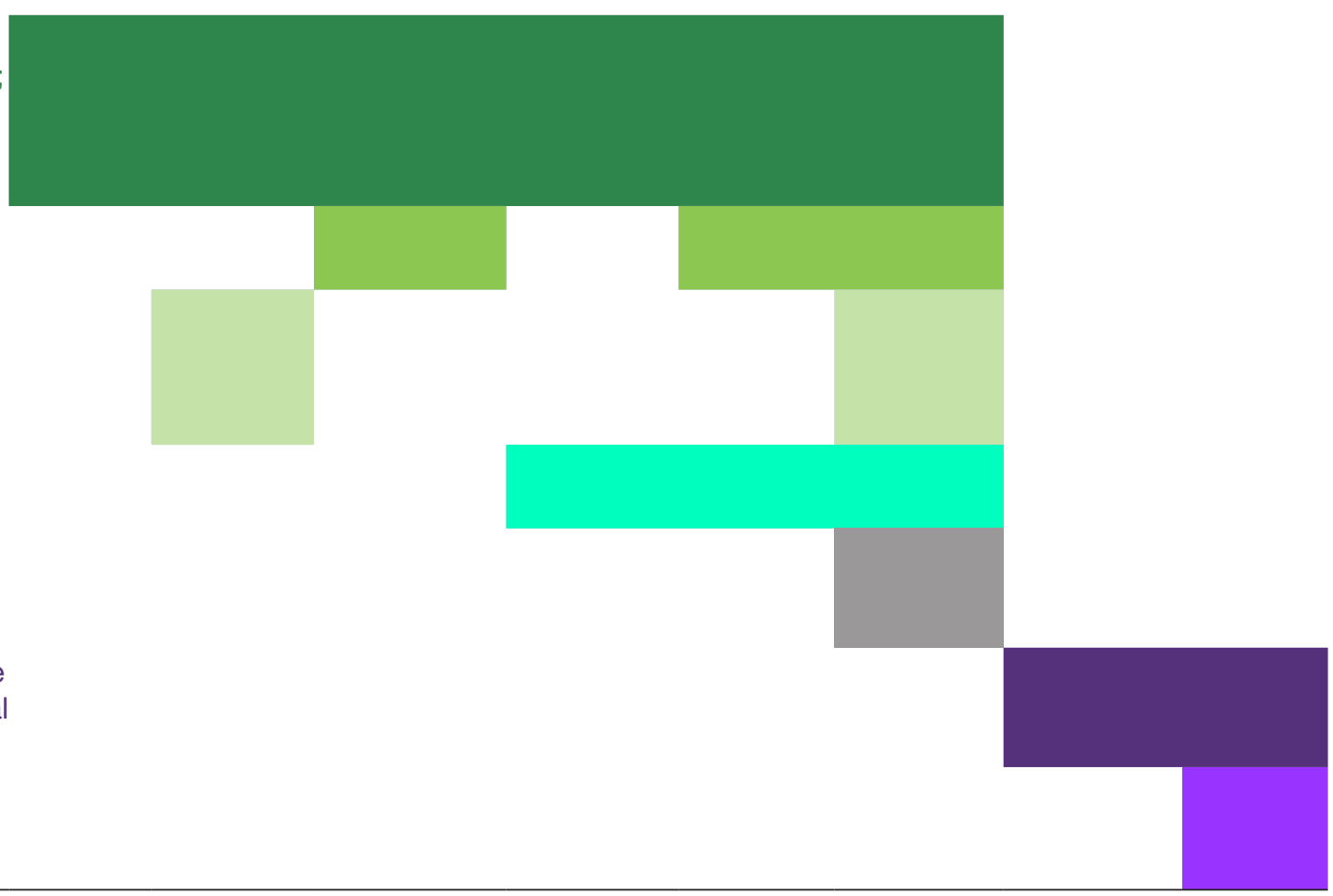

PHC, primary health care; SHA, System of Health Accounts.

The indicators examined in the paper for testing the mooted options include: PHC expenditure per capita in USD (PHC_pc), PHC expenditure as a percentage of total CHE (PHC\%CHE), PHC domestic government expenditure as a percentage of $\mathrm{PHC}$ expenditure $\left(\mathrm{PHC}_{-}\right.$ gghed\% $\mathrm{PHC}$ ) and PHC domestic government expenditure as total domestic government expenditure on health (PHC_ggehd\%GGHED).

\section{RESULTS}

\section{Overview of CHE components}

Components of CHE by functions $(\mathrm{HC})$

Data from the 36 countries shows that the largest component of CHE is curative care including both inpatient and outpatient care (more than 50\%). Taking a closer look at the distribution of curative care between inpatient and outpatient care, we can see that, on aggregate, inpatient care represents about $40 \%$ of total curative care expenditure (and outpatient care close to 60\%). The next largest items in CHE are expenditure on medical goods provided outside of a health service (mostly in pharmacies). Expenditure on preventive care, or on health system governance, represents about only $10 \%$ of CHE. It should be noted that large variations exist between countries for each of these components (figure 1).
Components of CHE by providers (HP)

The distribution of CHE by provider shows that the largest recipients of CHE overall are hospitals (collecting over $30 \%$ of total CHE), followed by ambulatory care providers and retailers (collecting around 18\% each).

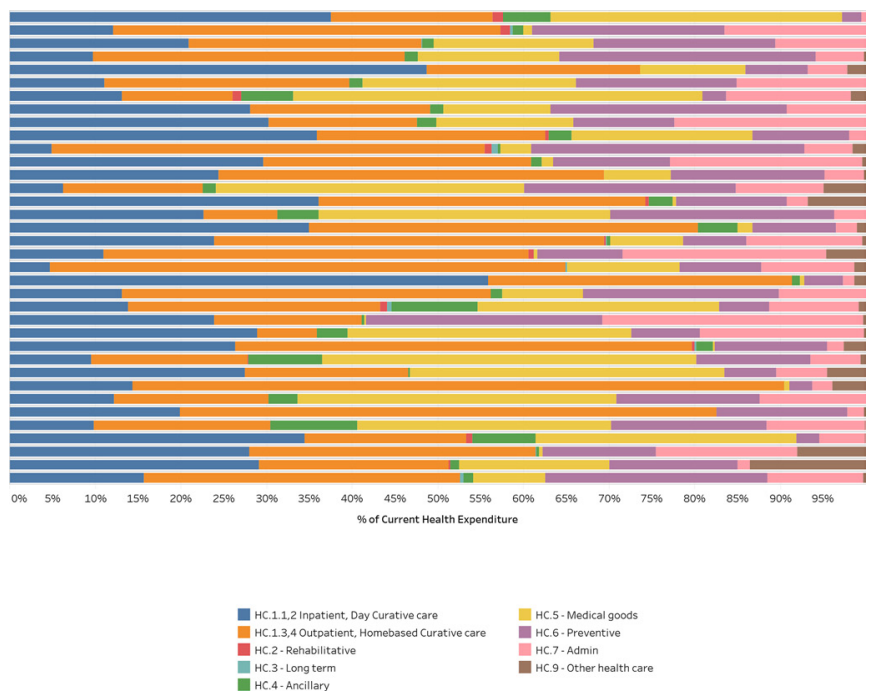

Figure 1 Current health expenditure by healthcare function $(\mathrm{HC})$. 


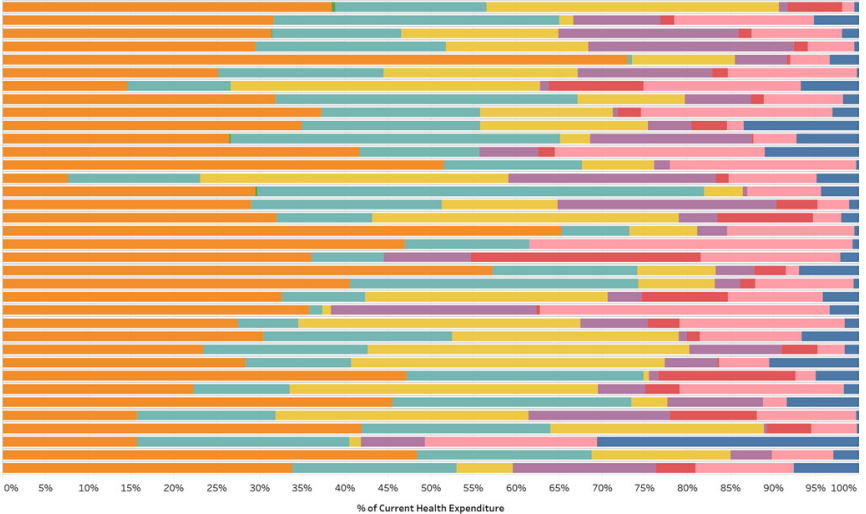

W. HP1 Hospitals

HP2 Residential long-term care faclilities

HPPAdmi

Figure 2 Current health expenditure by healthcare provider (HP).

On aggregate, expenditure on government agencies for administration of the health system outweighs expenditure on preventive care providers $(10 \%$ and $6 \%$, respectively). Different health systems use hospitals differently in relation to PHC. Some countries deliver more ambulatory care services in hospitals than other countries, and the role of district hospitals may be more prominent in some countries than others (figure 2).

\section{PHC expenditure measured by each option}

There is a wide range of country spending on PHC per capita, across countries and across definition options. Among the eight options, the IQR of PHC expenditure per capita is between US\$15 and US\$60 (figure 3A). Similarly, PHC expenditure as a percentage of CHE ranges from $31 \%$ to $88 \%$.

The significant difference occurs when medical goods provided outside of care is included, such as in options 3 and 5 . The median PHC expenditure increases by more than US\$13 per capita when medical goods are included. Options 6 and 8 are 'negative' options in that they are all inclusive, but inpatient care for option 6 or hospitals for option 8 also produce higher levels and shares of PHC (figure 3C-D).

\section{Consistency across options}

There is great interest on the part of countries to know not only how well they perform, which this paper does not address, but also how they compare with neighbouring countries, and so we tested how country expenditure rankings were affected by each of the eight options. For each indicator, countries were ranked by expenditure for each tested option. We tested the consistency of ranking by option by looking at the rank-order correlation between options. A high rank-order correlation was observed among options excluding medical goods provided outside of health services. In other words,
A

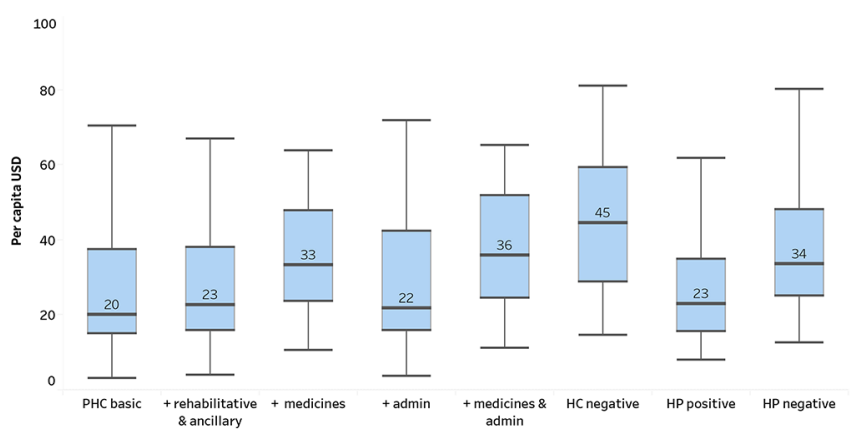

C

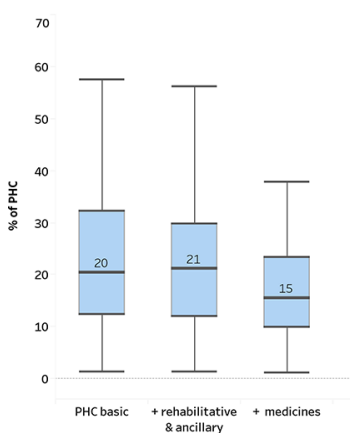

B

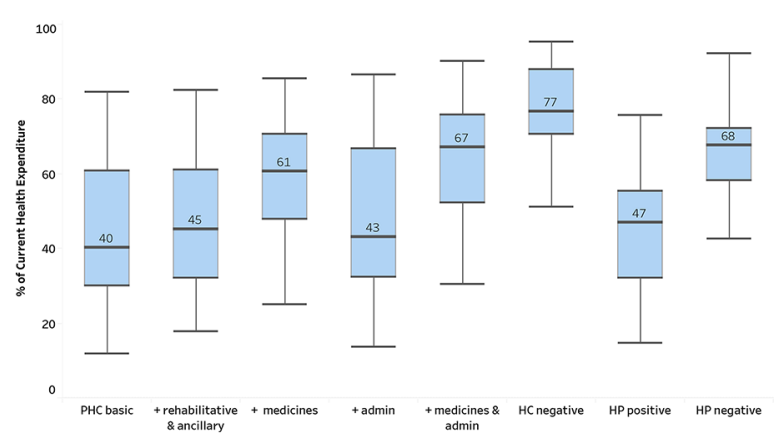

D

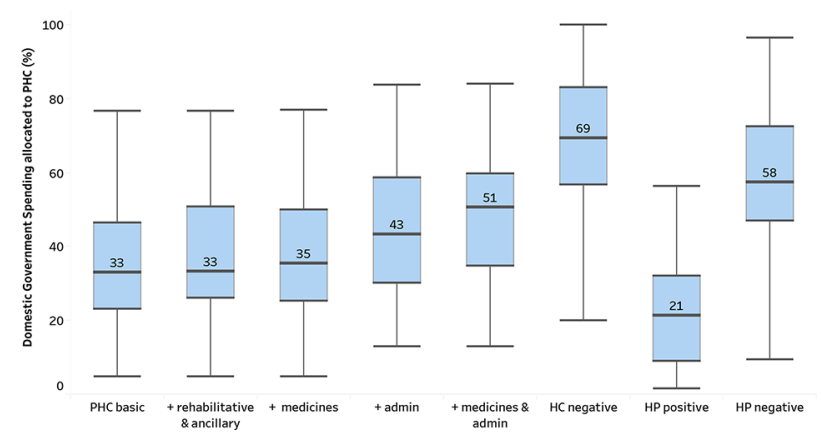

Figure 3 (A) PHC expenditure per capita USD. (B) PHC expenditure \% CHE. (C) Domestic government PHC expenditure $\%$ PHC. (D) Government spending allocated to PHC. Note: boxplots show the IQR (25th-75th percentile) of values with the median marked by a line inside the bar. The lines from the bars extend to the maximum and minimum values with outliers excluded. CHE, current health expenditure; PHC, primary healthcare. 
ranking is reshuffled when medical goods are included as it both increases the level and lowers the share of government paying for PHC (medical goods are typically purchased by the private sector). Similarly, the options 6 and 8 , where all providers are included except inpatient care for option 6 or hospitals for option 8, have a low correlation level with the basic option (table 2).

\section{Sensitivity analysis around medical goods provided outside of health services and around governance of health system}

Expenditure on medical goods provided outside healthcare services include both PHC medical goods following a first-contact healthcare service and non-PHC medical goods, such as for inpatient services or specialised outpatient services. As the inclusion of medical goods in an option has significant impact on PHC expenditure results, we ran a sensitivity analysis of variations among the share of expenditure of medical goods added to basic PHC expenditure. And as policymakers want to monitor the role and prioritisation of government expenditure towards PHC, panels (A) and (B) in figure 4A, B show the impact of medical goods in PHC on domestic government expenditure on PHC as a share of PHC. The graph confirms that the more we include of medical goods, the lower the share of PHC financed by government. Between no medical goods (basic PHC) to $100 \%$ of medical goods expenditure included, the share of domestic government expenditure on PHC in total PHC expenditure drops from $20 \%$ to $16 \%$ figure $4 \mathrm{~A}$.

Similarly, expenditure on health system governance and administration may not be entirely dedicated to supporting and developing PHC. Because these expenditures are typically paid by government, including $100 \%$ or less of expenditure on governance will have an impact on the monitoring of how much PHC is paid by government. From panels (A) and (B) of figure 4, we can see the important impact of adding the relative share of governance expenditure to PHC expenditure estimates. The lower the share of PHC financed by government starts at $25 \%$ of PHC (basic PHC no governance), rising up to $27 \%$ $(50 \%), 30 \%(80 \%)$ and finally to $34 \%$ of PHC. (Note that on the overall PHC expenditure, adding expenditure on governance has less impact than adding medical goods.)

\section{DISCUSSION}

While recognising the increasing demand from country policymakers and from the international community for PHC expenditure information, measuring PHC expenditure so that it can be used for cross-country comparisons and longitudinal comparisons is not an easy task. The challenges are many and interpreting results requires caution. Without providing an exhaustive list, we highlight some key issues that are relevant to interpreting the results.

\section{The choice between function and provider classification in SHA 2011}

At the conceptual level and for cross-country comparisons, the healthcare function classification (healthcare services) better captures the essence of PHC and first-contact services. However, health expenditure data is rarely broken down by function and producing expenditure by function involves assumptions and estimations based on information beyond health expenditure (eg, utilisation data). The provider classification has clearer boundaries and data by provider is relatively easy to collect. But it departs from PHC in that first-contact services can be provided in all settings. Because of the huge variation in service delivery settings, PHC expenditure based on function classification would be better suited for cross-country comparisons.

\section{Among service-based PHC expenditure options (1-6), medical goods provided outside healthcare services play a big impact on results}

Expenditures on medical goods in SHA 2011 include their use for both inpatient and outpatient services. Theoretically, PHC should only include outpatient use. The results show that the higher the proportion of medicine expenditure allocated to PHC results in lower share of total PHC expenditure funded by government. This is largely due to the fact that most of the expenditure on medical goods is paid through out-of-pocket payment in most countries. Government spending on PHC as a percentage of total PHC expenditure is a very important indicator for policymakers. The inclusion of expenditure on medicines may lead to different conclusions. Closer examination of medical goods expenditures by source would provide a more comprehensive picture.

Governance expenditure includes spending by mainly government agencies, such as ministries and local health authorities. Private agencies, such as private health insurance administration agencies, are often very small in the countries included in this analysis. Part of governance expenditure relates to $\mathrm{PHC}$, such as development and implementation of regulations, and policies for both individual-based and population-based interventions. The size of the governance expenditure as well as the proportion of governance expenditure allocated to PHC has an impact on the indicators of government spending on PHC as a percentage of total PHC and the percentage of total government spending on health allocated to PHC. Typically we would expect to interpret more government expenditure on PHC as a positive indicator. However, caution in this interpretation is encouraged if higher levels of government expenditure are driven in part by a large governance component. In addition, large government spending in particular the dominant proportion of personnel cost on the administration of health systems could also be an indication of inefficiency.

\section{In provider-based options, inconsistent definitions for 'hospital' may be a cause of downward bias in PHC expenditure}

The definition and the function of hospitals vary hugely. In some countries, hospitals only provide inpatient services, while in other countries, hospitals may provide outpatient curative care services, which are excluded automatically 
Table 2 Rank-order correlation among options

\begin{tabular}{llllllll}
\hline & $\begin{array}{l}\text { Ranking } \\
\text { definition 1 }\end{array}$ & $\begin{array}{l}\text { Ranking } \\
\text { definition 2 }\end{array}$ & $\begin{array}{l}\text { Ranking } \\
\text { definition 3 }\end{array}$ & $\begin{array}{l}\text { Ranking } \\
\text { definition 4 }\end{array}$ & $\begin{array}{l}\text { Ranking } \\
\text { definition 5 }\end{array}$ & $\begin{array}{l}\text { Ranking } \\
\text { definition } 6\end{array}$ & $\begin{array}{l}\text { Ranking } \\
\text { definition 7 }\end{array}$ \\
$\mathbf{8}$
\end{tabular}

\section{PHC as a percentage of CHE}

\begin{tabular}{|c|c|c|c|c|c|c|c|c|}
\hline $\begin{array}{l}\text { Ranking } \\
\text { definition } 1\end{array}$ & 1.0 & & & & & & & \\
\hline $\begin{array}{l}\text { Ranking } \\
\text { definition } 2\end{array}$ & 1.0 & 1.0 & & & & & & \\
\hline $\begin{array}{l}\text { Ranking } \\
\text { definition } 4\end{array}$ & 1.0 & 1.0 & 0.6 & 1.0 & & & & \\
\hline $\begin{array}{l}\text { Ranking } \\
\text { definition } 6\end{array}$ & 0.4 & 0.5 & 0.8 & 0.5 & 0.8 & 1.0 & & \\
\hline $\begin{array}{l}\text { Ranking } \\
\text { definition } 7\end{array}$ & -0.1 & 0.0 & 0.4 & -0.1 & 0.4 & 0.3 & 1.0 & \\
\hline $\begin{array}{l}\text { Ranking } \\
\text { definition } 2\end{array}$ & 1.0 & 1.0 & & & & & & \\
\hline $\begin{array}{l}\text { Ranking } \\
\text { definition } 3\end{array}$ & 0.9 & 0.9 & 1.0 & & & & & \\
\hline $\begin{array}{l}\text { Ranking } \\
\text { definition } 4\end{array}$ & 1.0 & 0.9 & 0.8 & 1.0 & & & & \\
\hline $\begin{array}{l}\text { Ranking } \\
\text { definition } 5\end{array}$ & 0.8 & 0.8 & 1.0 & 0.8 & 1.0 & & & \\
\hline $\begin{array}{l}\text { Ranking } \\
\text { definition } 6\end{array}$ & 0.7 & 0.7 & 0.8 & 0.8 & 0.9 & 1.0 & & \\
\hline
\end{tabular}


Table 2 Continued

\begin{tabular}{|c|c|c|c|c|c|c|c|c|}
\hline & $\begin{array}{l}\text { Ranking } \\
\text { definition } 1\end{array}$ & $\begin{array}{l}\text { Ranking } \\
\text { definition } 2\end{array}$ & $\begin{array}{l}\text { Ranking } \\
\text { definition } 3\end{array}$ & $\begin{array}{l}\text { Ranking } \\
\text { definition } 4\end{array}$ & $\begin{array}{l}\text { Ranking } \\
\text { definition } 5\end{array}$ & $\begin{array}{l}\text { Ranking } \\
\text { definition } 6\end{array}$ & $\begin{array}{l}\text { Ranking } \\
\text { definition } 7\end{array}$ & $\begin{array}{l}\text { Ranking } \\
\text { definition } \\
8\end{array}$ \\
\hline $\begin{array}{l}\text { Ranking } \\
\text { definition } 1\end{array}$ & 1.0 & & & & & & & \\
\hline $\begin{array}{l}\text { Ranking } \\
\text { definition } 2\end{array}$ & 1.0 & 1.0 & & & & & & \\
\hline $\begin{array}{l}\text { Ranking } \\
\text { definition } 3\end{array}$ & 1.0 & 1.0 & 1.0 & & & & & \\
\hline $\begin{array}{l}\text { Ranking } \\
\text { definition } 4\end{array}$ & 0.9 & 0.9 & 0.9 & 1.0 & & & & \\
\hline $\begin{array}{l}\text { Ranking } \\
\text { definition } 5\end{array}$ & 0.9 & 0.9 & 0.9 & 1.0 & 1.0 & & & \\
\hline $\begin{array}{l}\text { Ranking } \\
\text { definition } 6\end{array}$ & 0.8 & 0.8 & 0.8 & 0.9 & 0.9 & 1.0 & & \\
\hline $\begin{array}{l}\text { Ranking } \\
\text { definition } 7\end{array}$ & 0.7 & 0.7 & 0.7 & 0.7 & 0.7 & 0.6 & 1.0 & \\
\hline $\begin{array}{l}\text { Ranking } \\
\text { definition } 8\end{array}$ & 0.7 & 0.7 & 0.7 & 0.8 & 0.8 & 0.9 & 0.7 & 1.0 \\
\hline
\end{tabular}

CHE, current health expenditure; GGHED, Domestic General Government Health Expenditure; PHC, primary health care.

from the provider approach. This is the key source of the discrepancies between HC-based and HP-based options and partially explains why HC-based definitions better capture first-contact PHC services.

\section{Data gap is a big challenge}

Although not unique to measuring PHC expenditure, data availability and data quality challenge the robustness of the presented estimates. Underlying health information is often not reported at the level of granularity proposed in the SHA 2011 framework. For example, breakdown of

$$
\text { A } 80
$$

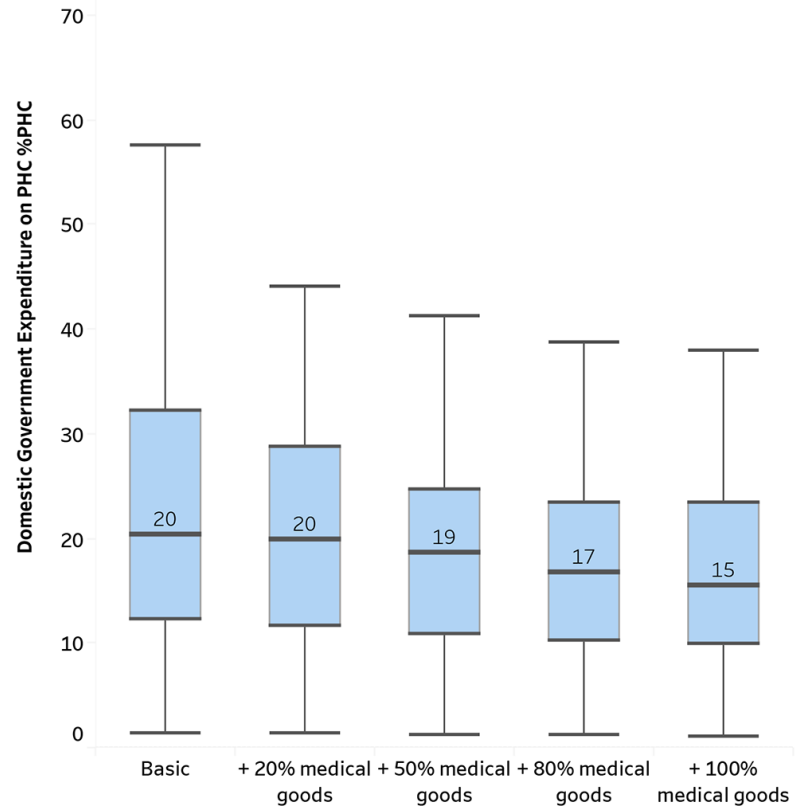

expenditures by general outpatient, dental and specialised outpatient are typically not available from country administrative records. Most countries included in this study do not have data disaggregated between specialised curative care and general outpatient curative care.

\section{The way forward}

The demand for standardised international monitoring of PHC expenditure is clear. Looking forward, the challenge posed by the lack of a clear operational definition of PHC will need to be addressed to support methodological

B 80

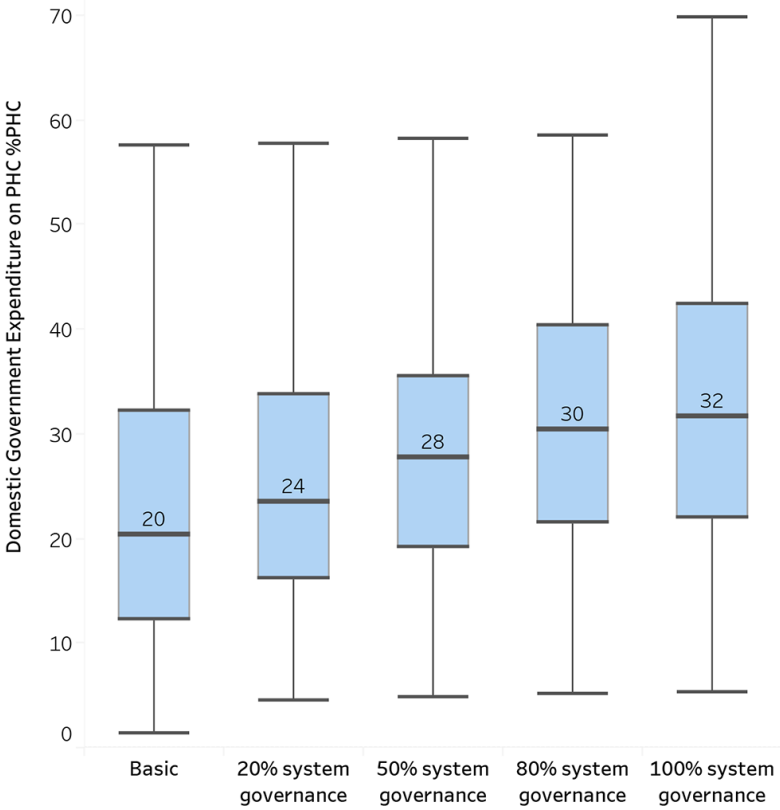

Figure 4 Domestic government expenditure on primary healthcare $(\mathrm{PHC})$ as a percentage of $\mathrm{PHC}$ expenditure. Note: boxplots show the IQR (25th-75th percentile) of values with the median marked by a line inside the bar. The lines from the bars extend tothe maximum and minimum values with outliers excluded. 
development. Further research and analysis would provide a clearer operational definition of PHC expenditures and more distinct PHC boundaries.

In parallel, the monitoring of PHC expenditure could test the possibility to add chosen granularity to SHA 2011. More granular data and strengthened data estimation methods would support a more robust or precise mapping of PHC to the SHA classifications and improve comparability between countries. The methodology for estimating PHC expenditure tested in this paper should be further elaborated to propose an improved standardised approach. Recommendations for triangulating PHC expenditure results and validating the quality of the results produced still need to be developed.

Alternatively, to test the pertinence of monitoring PHC expenditure using the SHA 2011 framework, countries will need to define how best to use SHA 2011 in coherence with the national PHC strategies. Lessons learnt and recommendations from country experience would inform the adaptation of the SHA for monitoring PHC expenditure. The process of producing SHA 2011 estimates would benefit from more information on data collection efforts for monitoring PHC expenditure, including household survey questionnaires which facilitate estimation of out of pocket spending and data on government budget spending at PHC level as defined by the country, increased facility-based data collection and leveraging routine information systems.

Finally, the options and indicators discussed in this paper are only a starting point for policy dialogue. To understand why one country spends more than another requires in-depth studies. In any given service delivery system, what providers are best placed to provide different types of services and how these services should be financed to promote efficiency and equity are extremely important.

\footnotetext{
Acknowledgements The paper benefited from the valuable comments and suggestions of Baktygul Akkazieva, Annie Chu, Camilo Cid, Ilker Dastan, GraceKabaniha, Awad Mataria, Claudia Pescetto, Lorena Prieto, Lluis Viñals Torres, Hui Wang, Callum Brindley, Veneta Cherilova, GregoryCoudrier, Chandika Indikadahena, Tomas Roubal, Hapsa Touré, and Lisa Fleisher. We would like to thank all those whocontributed in the consultation process, and whose inputs helped prepare thedefinitional options: Anshu Banerjee, Erica Barbazza, Shannon Barkley,Gabriella Flores, Ann-Lise Guisset, Odd Hansen, Karen Kinder, Iona Kruse,Blerta Maliqi, Viviana Martinez-Bianchi, Hernan Montenegro, David Morgan,Michael Mueller, Mikael Ostergren, Karen Stenberg, Tessa Tan Torres Edejer,Juan Tello, and colleagues from WHO country offices, including the Bangladeshcountry office. The consultation also benefited from inputsfrom the International Health Policy Program of Thailand; Dr. PiyaHanvoravongchai (Thailand); Dr. Neil Thalagala (Sri Lanka); India Ministry ofHealth (NHRM). The methodological work was developed incollaboration with the OECD. We would like to acknowledge the contribution ofDavid Morgan and Michael Mueller from OECD. We would like to thank Dana Hovig and JeanKagubare for their valuable contribution and suggestions. We would also like to acknowledge countryproducers of health accounts, which allowed us to test options for monitoringprimary health care expenditure. We appreciate the financial support of theBill and Melinda Gates Foundation to the global health expenditure tracking program. The work also benefited from the funding support of Gavi, the Global Fund, andUSAID. The views and opinions expressed in thisarticle are those of the authors.
}

Contributors NVM, KX and AS led the overall design and the development of the methodology. MA conducted the data analysis and figures/tables production. LF contributed to the literature review and preparing and analysing the data. All coauthors contributed to writing and interpreting the results.

Funding Financial support were received from the Bill and Melinda Gates Foundation, Gavi, The Global Fund, USAID, DFID, European Commission and the governments of Japan, France, Luxembourg for Global Health Expenditure Tracking program which made the data available for this study.

Competing interests None declared.

Patient consent for publication Not required.

Provenance and peer review Not commissioned; externally peer reviewed.

Open access This is an open access article distributed in accordance with the Creative Commons Attribution Non Commercial (CC BY-NC 4.0) license, which permits others to distribute, remix, adapt, build upon this work non-commercially, and license their derivative works on different terms, provided the original work is properly cited, appropriate credit is given, any changes made indicated, and the use is non-commercial. See: http://creativecommons.org/licenses/by-nc/4.0/.

\section{REFERENCES}

1. ECD, Eurostat and World Health Organization. A system of health accounts 2011: revised edition. Paris: OECD Publishing, 2017.

2. Kruk ME, Porignon D, Rockers PC, et al. The contribution of primary care to health and health systems in low- and middle-income countries: a critical review of major primary care initiatives. Soc Sci Med 2010;70:904-11.

3. Starfield B, Shi L, Macinko J. Contribution of primary care to health systems and health. Milbank Q 2005;83:457-502.

4. Atun R. What are the advantages and disadvantages of restructuring a health care system to be more focused on primary care services? Copenhagen: WHO Regional Office for Europe, 2004.

5. Bitton A, Ratcliffe HL, Veillard JH, et al. Primary health care as a foundation for strengthening health systems in low- and middleincome countries. J Gen Intern Med 2017;32:566-71.

6. Engström S, Foldevi M, Borgquist L. Is general practice effective? A systematic literature review. Scand J Prim Health Care 2001;19:131-44.

7. Kringos D, Boerma W, Bourgueil $Y$, et al. The strength of primary care in Europe: an international comparative study. Br J Gen Pract 2013;63:e742-50.

8. Phillips RL, Bazemore AW. Primary care and why it matters for U.S health system reform. Health Aff 2010;29:806-10.

9. Rao M, Pilot E. The missing link--the role of primary care in global health. Glob Health Action 2014;7.

10. Stigler FL, Macinko J, Pettigrew LM, et al. No universal health coverage without primary health care. The Lancet 2016;387.

11. Veillard J, Cowling K, Bitton A, et al. Better measurement for performance improvement in low- and middle-income countries: the primary health care performance Initiative (PHCPI) experience of conceptual framework development and indicator selection. Milbank Q 2017;95:836-83.

12. Nayar A, Chatterjee S. Primary health care reforms key to achieving universal health coverage. The Star. Journal of the American Board of Family Medicine 2018;16.5.:412-22.

13. Shi L, Macinko J, Starfield B, et al. The relationship between primary care, income inequality, and mortality in US states, 1980-1995. The Journal of the American Board of Family Medicine 2003;16:412-22.

14. Gurkan A, Kaiser K, Voorbraak D. Implementing public expenditure tracking surveys for results: lessons from a decade of global experience.

15. Maeda A, Norris Harrit M, Mabuchi S, et al. Creating evidence for better health financing decisions: a strategic guide for the institutionalization of national health accounts. The World Bank, 2012.

16. World Health Organization. The world health report 2008 : primary health care now more than ever : introduction and overview 2008.

17. World Health Organization and the United Nations Children's Fund (UNICEF), 2018. Available: https://www.who.int/docs/default-source/ primary-health/declaration/gcphc-declaration.pdf 